\title{
La Reforma del Sistema de Salud de los Estados Unidos de América en los Años '90
}

\author{
US Health Care Reform \\ during the 90 's
}

Trajano Augustus Tavares Quinhoes ${ }^{1}$

Sonia Fleury 2

\footnotetext{
${ }^{1}$ Economista, alumno de doctorado en Administración en la Escuela Brasileña de Administración Pública y de Empresas - EBAPE/FGV. trajano@fgvmail.br

${ }^{2}$ Doctora en Ciencias Políticas en IUPERJ, profesora de la Escuela Brasileña de Administración Pública y de Empresas - EBAPE/FGV. Miembro del Consejo de Desarrollo Económico y Social del actual gobierno brasileño. sfleury@fgv.br
}

RESUMEN El objetivo de este artículo es describir el proceso de reformas desarrollado en el sistema de salud de los Estados Unidos en la década del '90, proceso desarrollado de acuerdo a una lógica individualista y de mercado, y realizar un análisis del impacto de las reformas en la performance del sistema. Se llevó a cabo una investigación bibliográfica sobre el asunto tratado, y a partir de ella se realizó la descripción del sistema de salud y el análisis de las reformas, siguiendo la metodología de Evans (1), que propone un abordaje integrado de las dimensiones de organización y gestión, de financiamiento y de atención y provisión.

Observamos que el sistema de salud de los Estados Unidos continúa centrado en los valores del individualismo y de la competencia, compatibilizando medidas de protección pública a grupos sociales específicos con la producción de servicios regidos por el mercado. El predominio de la lógica de mercado no ha impedido la creciente intervención del Estado en la búsqueda de su regulación. Finalmente, se puede constatar que si bien la competencia ha permitido el desarrollo de innumerables innovaciones en la gestión financiera, permitiendo el avance de la eficiencia en el nivel micro de la gestión, el creciente aumento del gasto total en salud como porcentaje del PBI y la persistencia de una parte significativa de la población sin cobertura, Ilevan a la conclusión de que el sistema no es eficiente en el nivel macro.

PALABRAS CLAVE Reforma del Sector Salud; Programas Controlados de Atención en Salud; Conflicto de Intereses; Eficiencia; Regulación Gubernamental.

\begin{abstract}
This article's objectives are to describe the health care reform process during the 90's in the United States of America and to analyze its consequences for health system performance. We performed a literature search on US health care reform during the 90's. The methodology of analysis was taken from Evans (1), who developed an approach that integretes the dimensions of organization and management, financing and, attention and provision.

We verified that the US health care system continued to be based upon individualism and competition, combining actions of public protection for specific social groups with the production of services by the market. The market's logic has not prevented growing state intervention through regulation. Competition generated many innovations in financial management, which improved efficiency at the micro level. Nevertheless, the increase of total health care expenditures as a percentage of GDP and the existence of a significant part of the population without coverage, highlight the inefficiency of the system at the macro level.
\end{abstract}

KEY WORDS Health Sector Reform; Managed Care Programs; Conflict of Interest; Efficiency; Government Regulation. 


\section{INTRODUCCIÓN}

Los sistemas de salud se encuentran ante importantes desafíos. En las últimas décadas, se han buscado en todo el mundo mejores formas de regular, financiar y prestar servicios de salud. Una diversidad de países, de todos los niveles de desarrollo y con todos los sistemas políticos, ha realizado procesos de reforma en sus sistemas sanitarios en un sentido de innovación eminente. El resultado final es incierto, pero es posible que la búsqueda conduzca a nuevos modelos conceptuales y prácticos para los sistemas de salud (2).

Este estudio busca realizar un análisis de la reforma del sistema de salud norteamericano en los años '90 y verificar sus resultados en función de la integralidad, la eficiencia y la equidad en los cuidados de salud. Pretendemos también verificar si el reciente proceso de reforma en Estados Unidos significó una rediscusión de su modelo sanitario o sólo algún tipo de readecuación.

En la década del '90 se realizaron intensos debates en los EE.UU. con respecto al diseño del sistema de cuidados de la salud, que condujeron a la propuesta de reforma radical de 1993, a las reformas focalizadas de 1996 y 1997 y a las contrarreformas de 1999 y 2000.

Estas propuestas tuvieron su origen en problemas que se manifestaban desde hacía mucho tiempo. En los años '80 los gastos de salud en los EE.UU. aumentaron considerablemente con respecto a las décadas anteriores y con relación a los otros países de la Organization for Economic Co-operation and Development (OCDE). Esto ocurrió a pesar de los mecanismos implantados de control de gastos y de costos en salud. A comienzos de la década del ' 90 , las estimaciones para gastos sanitarios seguían siendo extremadamente elevadas y existía una expectativa de quiebra tanto para el sistema público como para el programa gubernamental de seguro de salud Medicare (a). Paralelamente, el número de personas sin cobertura continuaba siendo elevado y con tendencia creciente.

El resultado de las acciones implementadas en los años '90 fue limitado. El éxito del control de gastos realizado a mediados del decenio fue temporal y significó una reducción real mínima en su ritmo de crecimiento. Los planes de salud transfirieron a sus pacientes parte del costo de sus servicios, se redujo la cobertura, se impusieron las coparticipaciones (b), la reducción de servicios y la disminución de camas. Hubo un pequeño aumento de la cobertura, pero el número de no asegurados en el 2000 aún era alto, ya que alcanzaba los 38,7 millones, y superior al de 1990, que había sido de 34 millones.

Después de más de una década de cambios en el sistema de salud norteamericano, en los años 2000 y 2001 reaparecieron sus dos mayores problemas: se redujo la cobertura, registrándose un incremento de no asegurados y de sub-asegurados, y aumentaron los gastos en salud en el sector público y en el privado, en los gastos directos y en los co-pagos.

El momento actual es de crisis de perspectivas. Los intentos de control de gastos, topes máximos para la producción de servicios y énfasis en la competencia entre prestadoras y aseguradoras de salud no promovieron mayores niveles de eficacia, eficiencia o efectividad. El pesimismo y el determinismo actuales sobre las dificultades de lograr cambios en las curvas de gastos de largo plazo son diferentes a los consensos de la comunidad durante los años '70 y ' 80 .

El estudio del caso estadounidense es importante y la experiencia de la reforma de los años '90 es enriquecedora, entre otros aspectos, para el análisis de los instrumentos de gestión y contención empleados para el control de los gastos en salud. Este modelo sanitario es paradigmático, se basa en los seguros privados de salud y está centrado en una lógica de mercado. Según la tipología propuesta por Londoño y Frenk (2), puede caracterizarse como un modelo privado atomizado, donde las funciones de regulación, financiamiento y prestación se realizan separadamente, y en el que el financiamiento y la organización prestacional son verticalizadas y fragmentadas en grandes grupos. Estados Unidos es el ejemplo más importante de país organizado de esta forma y constituye además el único país desarrollado que aún enfrenta el problema de cobertura insuficiente de cuidados de salud.

Este trabajo se inicia con el análisis de los antecedentes de la reforma del sistema sanitario de los años '90. A continuación se describe el modelo de cuidados de salud norteamericano según tres ítems: gestión, cobertura y acceso y 
financiamiento. Luego se aborda la reforma del sistema de salud americano en los años '90 organizada en tres temas: contexto, iniciativas de reforma y resultados alcanzados. Finalmente, exponemos nuestras conclusiones, enfocadas en la experiencia de esa década, y analizamos sus efectos en el modelo de cuidados norteamericano y vemos qué lecciones pueden extraerse.

\section{ANTECEDENTES DE LA REFORMA}

Se describen a continuación, los principales antecedentes de la atención de la salud estadounidense, previos a la década del '90: la creación del Medicare y del Medicaid (c) en 1965, y la expansión del Managed Care (d) en los años '80. El objetivo de esta sección es identificar en estas iniciativas los elementos que condujeron a la situación que derivó en la reforma de mediados de los años '90.

\subsection{5 - CREACIÓN DEL MEDICARE Y EL MEDICAID, UN PAQUETE DE BENEFICIOS DE SALUD Y MEJORAS SIN PRECEDENTES EN LA SEGURIDAD SOCIAL}

La creación de los programas gubernamentales Medicare y Medicaid en 1965 fue consecuencia de un largo proceso, iniciado muchos años antes con la Seguridad Social y con las luchas políticas alrededor de la cuestión social en los EE.UU.

La política social estadounidense se caracteriza por su desarrollo tardío en comparación a Europa y América Latina: el seguro social fue iniciado en 1935, y por la participación reducida del sector público en la protección social. El capitalismo norteamericano transformó los principios del liberalismo en un código social e impuso valores como el individualismo, la protección a la propiedad privada y la necesidad de gobierno mínimo. Aunque tuvo un inicio tardío, el seguro norteamericano mantuvo una tendencia expansiva e incremental, tanto en gastos como en cobertura y beneficios. La ausencia de grandes cambios en el modelo original de seguro de carácter restrictivo caracteriza la contradictoria y singular trayectoria norteamericana (3).

La confianza en el mercado y la familia y, por extensión, en las organizaciones comunitarias como canales de respuesta a las demandas sociales, determinó el predominio de las instituciones privadas filantrópicas en asuntos sociales. En 1904, solamente 485 de las 4.207 instituciones de beneficencia en los EE.UU. eran públicas y atendían a menos de un tercio de los internos; hacia 1927, el gasto privado filantrópico excedía los mil millones de dólares, mientras que el gasto público alcanzaba los 161 millones, considerando todos los niveles de gobierno. Estas acciones estaban inspiradas en las Poor Laws inglesas, que clasificaban a las personas en poor o pauper, es decir, descuidados y flojos, y buscaban restaurar la capacidad de los individuos para autosostenerse y enfrentar la "pauperización" con penas y pérdida de derechos civiles (3).

A comienzos del siglo XX, la agenda gubernamental empezó a cambiar. Con el crecimiento del desempleo en las ciudades, los gobiernos locales adoptaron algunas medidas de protección, como la creación de abrigos para los miserables (almshouses), lo que incrementó los gastos sociales y la reivindicación de un nuevo tratamiento de las demandas sociales por parte del sector público. Los ancianos surgieron como una preocupación entre los años 1900 y 1929, mientras se desarrollaba, con menor intensidad, la lucha de los trabajadores por el Seguro Social.

Sin embargo, estos asuntos recién tuvieron un marco legal en 1935, después de la campaña electoral de 1934, cuando las cuestiones sociales se tornaron importantes. Las consecuencias de la crisis de 1929 y de la Gran Depresión fueron los hechos que cambiaron la historia de esos años y precipitaron la emergencia de la dimensión social.

El Social Insurance Act, de 1935, fue una expansión sin precedentes del rol del gobierno federal, que retiró el problema de la ancianidad de la responsabilidad del voluntariado. La propuesta era simple: planteaba que los beneficios serían proporcionales a las ganancias y se pagarían solamente a quienes los costeaban, que la cobertura sería limitada y que el sistema debía acumular reservas y autofinanciarse. La legislación posterior respetó el sistema básico de protección, pero alteró sus principios originales.

La estructura del sistema de protección social reflejaba el compromiso entre las ideas de 
la sociedad norteamericana acerca del individualismo, la libertad y la independencia, y el impacto causado por la crisis de 1929, que había debilitado la fe en la infalibilidad del mercado y los principios de culpabilidad del necesitado y de no interferencia estatal (3).

El Seguro Social evolucionó en base a enmiendas a la legislación social de 1935. Las sucesivas enmiendas de los años 1939, 1952, 1954, 1956 y 1958 fueron todas de carácter liberal y convirtieron al sistema en bipartidario. Este proceso, iniciado en 1935 por un presidente demócrata, tuvo su momento de mayor expansión con un presidente republicano: Eisenhower. Las sucesivas reformas permitieron ampliar la cobertura, y diversificar e incluir beneficios no relacionados a contribuciones pretéritas; también produjeron el incremento continuo del valor de los beneficios y de las contribuciones, y los cambios en el financiamiento por repartición simple. Sin embargo, a pesar de las enmiendas, no hubo cambios profundos: apenas se modificó la atención de demandas específicas.

Fue necesario esperar otra década para que las resistencias fueran vencidas y surgieran los programas de salud al interior de la estructura del Seguro Social, en los años '60. La tendencia a la ampliación de la asistencia inició los cambios con los programas de asistencia médica para ancianos, el Medicare, y la asistencia médica para los pobres, el Medicaid, ambos en 1965 (3).

La coyuntura de los años ‘60 permitió la creación de estos programas, venciendo resistencias y debilitando la ideología liberal. Por primera vez, la igualdad apareció como una problemática política, como parte de las estrategias de combate a la pobreza y la discriminación de las minorías, como consecuencia de la politización del problema racial. La problemática de la igualdad de derechos dejó de ser vista como una mera consecuencia de la igualdad de oportunidades, requiriendo medidas de discriminación positiva. Es necesario recordar que en los gobiernos de los presidentes Kennedy y Johnson hubo circunstancias especiales, como el retorno de los demócratas al poder, una amplia mayoría en el Congreso, la promesa de la liberación de los pueblos de Vietnam y de prosperidad para los pobres de América, y el apoyo de la burocracia del Seguro Social a las medidas expansionistas (3).
La creación de los seguros públicos de salud gubernamentales Medicare y Medicaid fue probablemente la mayor modificación realizada en el sistema sanitario norteamericano en el siglo XX. Su implantación se dio en medio de interminables polémicas con los médicos, en especial la American Medical Association (AMA), que rechazaba cualquier forma de intervención estatal.

Pero si en la década del '60, Medicare y Medicaid contribuyeron a disminuir las desigualdades en salud, ampliando el acceso a los servicios y la cobertura, en los años '70 serían responsables del aumento en los presupuestos federal y estatal. Según Lobato (4), al inicio de la década del '70, los servicios médicos fueron objeto de un programa de estabilización económica que congeló precios y creó agencias específicas -Professional Standards Review Organizations-, para monitorear y controlar los costos de los servicios prestados a los programas gubernamentales. Almeida refiere que las medidas no tuvieron efecto, ya que inmediatamente después del fin del congelamiento los precios aumentaron nuevamente y estas agencias fueron rápidamente controladas por las organizaciones médicas (4).

Los precios de los servicios médicos y hospitalarios prestados al Medicare estaban basados en el sistema fee-for-service, cuyo valor tenía como base el sistema conocido como UCR (usual, customary and reasonable), o de acuerdo con el promedio tradicional de cobranza. De esa forma, según Enthoven, en los programas gubernamentales había un exceso permanente de demanda, dada por la combinación de un extenso seguro con un sistema de Guild Model (e).

\subsection{AÑOS ‘80 - EXPANSIÓN DEL MANAGED CARE}

"Agotada la fase de expansión y predominio de los valores y estrategias vinculadas al igualitarismo (1960-1980), se inauguró en los años ochenta una nueva etapa, con el recrudecimiento del individualismo y de las medidas de reducción del gasto social de la era Reagan" (Fleury, 1997). Se retomaba la ideología de la retirada del Estado de la protección social como forma de fortalecimiento de la propia sociedad, y se partía del principio que la retirada del gobierno central de esas actividades promovería un aumento de prosperidad, por el fortalecimiento 
del mercado y de los niveles locales. Los principales cambios fueron: el retroceso en la protección social exclusivamente para los desempleados; la revisión y restricción de los criterios de incorporación a los planes; la sustitución del rol del gobierno central de promotor de incentivos a normatizador; y el retorno de los programas a los estados y municipios, restringiendo la participación directa del gobierno central.

Si por un lado la ideología era bastante clara, la realidad era demasiado compleja debido a la reducción de los gastos sociales y los recortes de partidas presupuestarias en los programas federales.

Los recortes en Medicare y Medicaid eran difíciles de ser realizados, tanto por razones sociales -ya que afectaba a individuos con necesidades urgentes, en condiciones mínimas para resolver sus problemas de salud y de sustentocomo por razones relativas a las estructuras de esos programas. El programa Medicare, por ejemplo, privilegia el uso de servicios médicos privados y de tecnología de alta complejidad, y cuenta con el apoyo de poderosos grupos de presión.

Los principales cambios en los años '80 en la salud norteamericana fueron la introducción de medidas eminentemente económicas, de control de gastos y de recorte de los beneficios. El Managed Care y la Managed Competition ( $f$,, que fueron algunas de las iniciativas más conocidas, serán analizadas más adelante.

Otro cambio importante fue la expansión de las Health Maintenance Organizations (HMOs) (g). Esta antigua forma de asistencia permaneció en segundo plano durante décadas. En sus inicios, enfrentada a la fuerte oposición de la corporación médica, fue apoyada por los movimientos de trabajadores y consumidores, que consideraban los planos de pre-pagos una forma más solidaria de asistencia y con mayor facilidad de control sobre la práctica profesional.

En 1973, por medio de la HMOs Act, el gobierno de Nixon se apropió del término y redefinió la práctica de grupo de pre-pagos acuñándola con el nombre de HMO. La principal característica de las HMOs en comparación con las aseguradoras de salud tradicionales era la práctica del Managed Care. Esto consistía en la imposición de controles sobre la oferta de servicios de salud a los prestadores de servicios y a los consumidores, con la finalidad de contener los costos, de preservar la hegemonía de los prestadores privados y para controlar el sistema de pagadores privados (5). Se creía que sustituyendo la regulación por la competencia, al mantener un sistema de mercado tipo managed competition o competencia administrada de Alain Enthoven, sería posible alcanzar mayor equidad. La competencia administrada alentaba la competencia en el mercado de servicios de salud como forma de promover la eficiencia y el acceso a los servicios, y para tal fin proponía la creación de los sponsors: consumidores inteligentes, públicos o privados, que actuarían según intereses de los consumidores finales, negociando precios, cobertura, tiempo de internación, etc. El mercado, restringido a la acción de dos grandes fuerzas, los terceros pagadores y los consumidores, superaría esta limitación al incluir a los sponsors (4).

El modelo HMO generó diversas formas similares, tales como:

- Preferred Provided Organizations: las diferencias con relación a las HMOs son la no obligatoriedad de consulta inicial al médico generalista, la posibilidad de recurrir a prestadores no incluidos en el plantel y menores riesgos a los portadores. Fue introducida en respuesta a las HMOs por los propios médicos, que negociaban descuentos con prestadoras específicas.

- Point of Service Plan: este sistema también permite consultar prestadoras fuera del plantel, pero los co-pagos son altos (4).

Los programas de atención administrada del tipo HMO presentan tres tipos básicos de organización: el staff model, en el que los médicos son contratados como asalariados directamente por la HMO para atender la clientela; el modelo de grupo, donde la HMO contrata empresas médicas para la atención de los integrantes de plan; y el modelo independent practice association, en el que se contratan a profesionales, solos o en pequeños grupos. Éste fue el tipo que más creció en la década del '80 (5).

Las diferentes formas de HMOs y el Managed Care se expandieron rápidamente en los años '80. La modalidad de pre-pagos se difundió entre los prestadores. 
Aunque la competencia administrada está sustentada en las fuerzas de mercado, una de las medidas más importantes en ese período tuvo un carácter regulador: el cambio del modelo de pagos a los servicios hospitalarios del Medicare, que no fue más por servicios sino por los Grupos Relacionados de Diagnóstico (GRD) (h). El sistema GRD modificó el sistema de pago de los servicios públicos: el Estado pasaba de simple repartidor de recursos a comprador de servicios, con lo que debió extender la burocracia para monitorear el nuevo sistema. El segmento hospitalario comenzó a utilizar el mismo sistema para el pago de los médicos no dependiente de hospitales.

Los gobiernos europeos constituyeron sus modelos de salud aboliendo la competencia, siguiendo un camino opuesto al norteamericano. La diferencia se explica, de acuerdo con Almeida (5), por la actuación de las corporaciones médicas. En el caso norteamericano, la AMA se opuso terminantemente a la incorporación de los médicos a ese tipo de práctica, mientras que en Europa fue precisamente el crecimiento de los seguros lo que movilizó a los médicos a organizarse contra las compañías aseguradoras y a presionar al Estado para obtener los retiros protegidos de la competencia del mercado. No es casual que las HMOs resurgieran en los EE.UU. justamente cuando imperaban las políticas de debilitamiento de las corporaciones médicas y se priorizaba la competencia entre los proveedores de cuidados.

El surgimiento de las HMOs como un actor importante en el sistema de salud tornó cada vez más detallada la administración de los servicios médicos hospitalarios, provocando tensiones entre los proveedores de servicios y las aseguradoras. Las dificultades impuestas al acceso a los servicios también ocasionaron conflictos entre las asociaciones de usuarios y de consumidores y las corporaciones médicas contra las aseguradoras.

Las HMOs también contribuyeron a la consolidación de los mercados locales y regionales, concentrando la oferta de servicios de salud, y al estrechamiento de las relaciones del complejo médicos-industria, intensificando la utilización de alta tecnología en equipamientos y fármacos. En ese período también se verificó la transnacionalización de esas empresas.
Otro aspecto de lo ocurrido en los años '70 y '80, fue la transformación de los hospitales sin fines de lucro en organizaciones de lucro, constituyendo administraciones empresariales muy poderosas. Estas organizaciones, surgidas en 1968, al principio representaban una parcela muy pequeña de las camas hospitalarias, pero a fines de los años '80 ya eran amplia mayoría (5).

En conclusión, verificamos que, mientras las reformas en los años '60 apuntaron a la inclusión y al aumento de la cobertura, las de los años '70 y '80 tuvieron un énfasis preponderante sobre el control de costos y de gastos en salud, alternando discursos y prácticas pro-regulación o pro-competencia. A pesar del continuo empeño financiero, como veremos más adelante, los gastos y los costos, con pocos momentos de alivio, permanecieron altos en los años '90, y el acceso a los cuidados en salud registró una tendencia declinante.

\section{EL MODELO DE CUIDADOS DE SALUD}

En esta sección se describe el modelo de cuidados de salud de EE.UU., subdividido en tres temas: gestión, cobertura y acceso, y financiamiento de servicios. De acuerdo a las funciones y a la tipología propuesta (i) por Londoño y Frenk (2), el caso estadounidense se aproxima al Modelo Privado Atomizado, puesto que contempla las funciones de prestación y de financiamiento; no contempla la función de modulación, y la de articulación no es efectuada específicamente por ningún agente, sino que es realizada entre los financiadores y los prestadores de servicios. La cuestión prestacional es abordada junto con cobertura y acceso, y el financiamiento está analizado en una sección aparte.

\subsection{GESTIÓN}

El sistema de salud norteamericano está compuesto por cuatro grandes sectores: el que depende del gobierno federal, el de los gobiernos estatales, el de los gobiernos locales (ciudades, condados y comarcas) y el sector privado.

Uno de los papeles prominentes del gobierno federal en el cuidado de salud es el de comprador de seguros de salud y de tercer pagador 
por cuidados. El gobierno federal es responsable de la atención de 39 millones de ancianos y personas discapacitadas, 9 millones de empleados del gobierno federal y sus dependientes, y 6 millones de militares activos y sus familiares. Financia también, junto con los estados, programas de seguros públicos para pobres y niños próximos a la pobreza. Provee directamente el sistema de cuidados en salud que atiende a los soldados veteranos. El sistema sanitario funciona, además, como receptor primario de información y constituye la principal fuente de financiamiento para los servicios de investigación. Notablemente, no asume la función de planeamiento nacional en salud.

Los gobiernos estatales son los responsables de regular la actividad de los proveedores de cuidados de salud y de las compañías aseguradoras, e impone los requerimientos pertinentes a la solvencia financiera, la calidad del seguro, los beneficios y otras características del seguro de productos. Ellos establecen licencias y requerimientos de certificación para hospitales, médicos y otros proveedores. Otro papel crítico de los estados es la administración y financiamiento, junto con el gobierno federal, de los programas públicos para proveer el seguro o el cuidado directo en salud para los niños y las familias pobres. Ellos también adquieren seguros de salud en nombre de los empleados del gobierno estatal, influenciando de este modo en los mercados locales. Hay una variación significativa en la forma en que los estados realizan sus actividades regulatorias, gerenciales y de adquisición de servicios. Los estados generalmente utilizan la tradición del profesionalismo como forma de auto-regulación para crear y promover compromiso con los patrones de desempeño y responsabilidad.

Los gobiernos locales, en conjunto con los estatales, asumen un papel importante en financiar la llamada "red de proveedores de seguridad" que sirve a los indigentes y mantiene los sistemas de servicios responsables por la emergencia.

La mayoría de las instalaciones de cuidados de salud es propia y operada por la iniciativa privada. Los planes de seguro de salud también son privados y la mayor parte opera con finalidad lucrativa, con la excepción significativa de los planes Blue Cross y Blue Shield. Algunos funcionan como contratantes para el Medicare y son responsables de funciones administrativas como el pago a las prestadoras de cuidados de salud y a los profesionales. En las últimas dos décadas, las HMOs surgieron como un actor importante y contribuyeron a la tendencia a la concentración y centralización en la provisión de servicios.

\subsection{COBERTURA y ACCESO}

La cobertura del sistema de salud norteamericano está segmentada en tres grandes grupos. La mayor parte de la población económicamente activa y sus dependientes está afiliada a planes de seguro-salud (j) provistos por el empleador.

El Medicare, programa federal de seguro social, cubre virtualmente a todos los ciudadanos mayores de 65 años y los calificados como discapacitados (después de un período de espera de dos años). Es un programa estandarizado, con un paquete de beneficios uniforme y decisiones centralizadas. No cubre la prescripción de medicamentos y muchos de los servicios preventivos han quedado afuera. Sus disposiciones de división de costos incluyen deducciones anuales, co-pagos y un límite en los beneficios que coloca a los asegurados en riesgo para los gastos por larga estadía en los hospitales. Muchos de los comprometidos con el programa tradicional tienen alguna forma de seguro complementario que cubre parte o todo el co-pago y que Ilena los vacíos del paquete de servicios. El mayor de estos seguros complementarios es el Medigap, cuyo mercado está fuertemente regulado por el gobierno y que cubre cerca de un tercio de los beneficiarios del Medicare.

El aporte financiero de Medicare puede dividirse en dos partes: la parte $A$, que paga los beneficios a los hospitales y el cuidado domiciliario calificado de enfermería, y la parte $B$, que contribuye a pagar las cuentas médicas y los servicios ambulatorios. El Medicare parte B es opcional y requiere el pago de una prima mensual. Hay algunas condiciones especiales para incorporarse a ese programa. Ciertos beneficiarios pueden presentar, además, las condiciones para el programa Qualified Medicare Beneficiary o el Special Low-Income Medicare Beneficiary, que pueden contribuir al pago de las deducciones y de los co-pagos. 
Medicaid y State Children's Health Insurance Program (SCHIP) sirven como una red de asistencia social que cubre a los más pobres y a aquellos cuyos gastos médicos consumen gran parte de su renta, extendiendo sus beneficios a los niños próximos a la pobreza.

Ciertas brechas en las condiciones de incorporación a los programas públicos, la incapacidad o la falta de disposición para adquirir un seguro privado y otras barreras para la afiliación, dejan a una parte significativa de la población sin cobertura de salud. Según Davis (6), en el año 2000, 13,3\% de la población de hasta 64 años estuvo sin cobertura durante todo el período anual y el $12,6 \%$ tuvo falta de seguro durante alguna parte del año. Considerando estos dos segmentos de la población, el $26 \%$ de las personas hasta los 64 años no tuvo cobertura en todo el año o parte de él, dejando su salud y finanzas en riesgo (7).

Los individuos que no cuentan con cobertura de seguro-salud tienen asegurado por ley el acceso a los servicios de emergencia. Los departamentos de emergencias están obligados a atender y estabilizar a cualquier paciente, independientemente de su seguro y capacidad de pago. Sin embargo, esta es una forma cara e ineficiente de proveer cuidados. Baker y colaboradores afirman que las personas no aseguradas tienen un $50 \%$ más de posibilidades de requerir atención de mayor complejidad, y también menores posibilidades de recibir cuidados preventivos y de rutina para evitar enfermedades crónicas (8).

El número de beneficiados por el Medicaid varió inversamente al nivel de la actividad y a los ciclos de la economía norteamericana. Creció casi $50 \%$ en la primera mitad de los años '90, como reflejo del lento comportamiento de la economía, y declinó cuando la producción aumentó y el desempleo disminuyó.

Los que cuentan con la doble cobertura de Medicare y Medicaid, utilizan el primero como pagador primario mientras que el segundo contribuye a cubrir el co-pago, las deducciones y el pago de los cuidados no cubiertos por el primero, como la prescripción de medicamentos y los cuidados de larga evolución. La capacidad de los estados para controlar la doble cobertura es limitada ya que que las provisiones federales permiten a los beneficiados del Medicare escoger libremente entre los prestadores. El Medicaid es el único gran proveedor de cuidados de larga duración, cuidados que no son cubiertos por el Medicare ni por la mayoría de los planes privados.

Según estadísticas del año 2000, el $86 \%$ de la población norteamericana posee seguro de salud. De esa parte de la población, $72,4 \%$ posee seguro privado $(64,1 \%$ basado en el empleador) y $24,2 \%$ presenta seguro de salud gubernamental. El beneficio gubernamental se distribuye en $10,4 \%$ del Medicaid, $13,4 \%$ del Medicare y $3 \%$ otorgado por las fuerzas militares (ver Cuadro 1).

La amplia mayoría de los no asegurados son pobres o casi pobres, pero no les otorgan seguros debido a que la mayor parte son empleados o pertenecen a una familia trabajadora. Los niños y jóvenes menores de 18 años son más propensos a ser asegurados y su cobertura aumentó en los años '90, como resultado del Programa SCHIP. El problema de acceso a los servicios de salud por parte de la población de baja renta se agrava aún más en la medida en que se les impone los mecanismos de desembolso y coparticipación (9).

La política de la mayor parte de las empresas de seguro privado es ofrecer planes a los empleadores tanto de pequeños como de grandes grupos, que son los que ofrecen la mayor distribución de riesgo. La legislación no obliga a los empleadores a asegurar a sus funcionarios, pero las facilidades tributarias los estimulan.

La mayoría de los empleadores grandes y medianos auto-financia la cobertura del seguro de salud de sus funcionarios. Los planes autofinanciados no son regulados ni por los estados ni por el gobierno federal, que no define pautas para el plan, la administración o la protección del consumidor. La ley federal ERISA, de 1974, prohibió que los estados normalicen, regulen $\mathrm{o}$ impongan tributos a esos planes.

Una parte relativamente pequeña de la población está cubierta directamente por los seguros sobre bases no grupales o por empresa (menos de $8 \%$ ). Ese mercado está caracterizado por un mayor costo administrativo. Para los que están enfermos, no se encuentran asegurados y buscan cobertura, el seguro ofrecido individualmente no suele ser atractivo ni accesible, porque en la mayoría de los estados, las primas se ajustan al riesgo según las características individuales, y frecuentemente se excluyen de la cobertura a las 
Cuadro 1. ESTADO DE COBERTURA Y DISTRIBUCIÓN DEL SEGURO DE SALUD POR TIPO, AÑO 2000.

\begin{tabular}{|c|c|c|c|c|c|c|c|c|}
\hline & \multirow{3}{*}{ TOTAL } & \multicolumn{6}{|c|}{ CUBIERTO POR SEGURO PRIVADO O POR EL GOBIERNO } & \multirow{3}{*}{$\begin{array}{l}\text { NO CUBIERTO } \\
\text { Sin seguro }\end{array}$} \\
\hline & & \multicolumn{2}{|c|}{ Seguro Privado } & \multicolumn{4}{|c|}{ Seguro de Salud Gubernamental } & \\
\hline & & Total & $\begin{array}{c}\text { Basado en el } \\
\text { empleador }\end{array}$ & Total & Medicaid & Medicare & Militar & \\
\hline \multicolumn{9}{|l|}{ PERSONAS } \\
\hline Total & 86,0 & 72,4 & 64,1 & 24,2 & 10,4 & 13,4 & 3,0 & 14,0 \\
\hline \multicolumn{9}{|l|}{ SEXO } \\
\hline Hombres & 85,1 & 72,8 & 65,3 & 22,2 & 9,4 & 12,0 & 3,3 & 14,9 \\
\hline Mujeres & 86,9 & 72,0 & 62,9 & 26,1 & 11,3 & 14,7 & 2,8 & 13,1 \\
\hline \multicolumn{9}{|l|}{ EDAD } \\
\hline Menos de 18 años & 88,4 & 70,5 & 66,2 & 23,3 & 20,4 & 0,7 & 2,9 & 11,6 \\
\hline 18 a 24 años & 72,7 & 64,8 & 53,4 & 11,9 & 8,7 & 0,6 & 2,9 & 27,3 \\
\hline 25 a 34 años & 78,8 & 72,1 & 68,1 & 9,0 & 6,3 & 1,1 & 2,2 & 21,2 \\
\hline 35 a 44 años & 84,5 & 78,6 & 74,3 & 8,7 & 5,4 & 1,8 & 2,6 & 15,5 \\
\hline 45 a 64 años & 87,4 & 79,4 & 72,6 & 12,5 & 4,6 & 5,5 & 3,3 & 12,6 \\
\hline Más de 64 años & 99,3 & 61,5 & 33,8 & 96,6 & 10,0 & 96,2 & 4,2 & 0,7 \\
\hline \multicolumn{9}{|c|}{ RENTA DE LA UNIDAD DOMICILIARIA } \\
\hline Menos de US\$25.000 & 77,3 & 41,2 & 27,6 & 52,4 & 27,7 & 28,7 & 2,6 & 22,7 \\
\hline US\$25.000 a US\$ 49.999 & 83,0 & 70,2 & 60,9 & 25,7 & 9,8 & 14,7 & 3,5 & 17,0 \\
\hline US\$ 50.000 a US\$ 74.999 & 89,0 & 83,3 & 77,4 & 13,5 & 4,3 & 7,1 & 3,2 & 11,0 \\
\hline US\$75.000 a más & 93,1 & 90,1 & 84,9 & 9,3 & 2,2 & 5,2 & 2,7 & 6,9 \\
\hline
\end{tabular}

Fuente: Oficina de Censos Americana. Encuesta sobre la población actual, marzo 2001, en la OECD (2003).

Nota: La suma de las columnas interiores de Seguro Privado y Seguro de Salud gubernamental no suman exactamente los totales por algunas coberturas menores o porque algunas personas cuentan con más de un seguro.

patologías pre-existentes y se cargan altas deductibilidades. Según Goldsmith (10), los individuos y pequeños grupos adquieren seguro-salud entre 30 y $40 \%$ más caro que los valores obtenidos por las grandes corporaciones.

Algunos estados y comunidades administran programas que proporcionan coberturas más accesibles para individuos y empleados en pequeños grupos. Ofrecen precios prorrateados en la comunidad, otorgando primas no sujetas a la suscripción médica. Estos mecanismos apuntan a minimizar la extensión en la valorización de las primas, independizándola de otros factores como el estado de salud o la edad.

Otro hecho, que menciona Fronstin (7), es que desde el año 1993 al 2000 los empleadores que ofrecían beneficios de salud a sus jubilados, mayores de 65 años, disminuyeron del $43 \%$ al $31 \%$, mientras que los empleadores que ofrecían seguro complementario al Medicare para los jubilados elegibles cayó de $40 \%$ al $24 \%$. La reducción de estos beneficios por parte de los empleadores se reflejó en un aumento de las inscripciones en los planes gubernamentales y en el contingente de no asegurados.

\subsection{FINANCIAMIENTO}

El financiamiento y la cobertura de los cuidados de salud en EE.UU. son atípicos comparados con los países de la OECD, en lo que se refiere, por ejemplo, a los pagadores múltiples y a las distintas fuentes de cobertura, que varían dependiendo de algunas características de la población como empleo, renta y edad.

Otra peculiaridad que se observa de la comparación con los países de la OECD es que mientras la mayoría de éstos presentó mayor crecimiento de los gastos de salud en las décadas de los '60 y '70 y una reducción en los años '80 y principalmente en los '90, en los EE.UU. ocurrió lo contrario. En los años '60 y '70, los gastos 
tuvieron un crecimiento real modesto con relación a la variación del $\mathrm{PBI}$, inferior al promedio de los países de la OECD. En los años '80, estos gastos casi duplicaron en datos reales la relación con el PBI y fueron 5,5 veces mayores que la variación promedio de los países de la OECD. En los años '90 hubo una reducción del crecimiento de gastos, pero con todo fueron superiores en un $44 \%$ al aumento promedio de los países de la OECD.

Casi tres cuartas partes de la población norteamericana está cubierta por seguros de salud privados, que corresponden a poco más de una tercera parte de los gastos (ver Cuadro 2). Esta estadística es a veces aprovechada como demostración de la eficiencia de los seguros privados en detrimento de los públicos, aunque no tiene en cuenta que atienden a grupos distintos y que el grupo de mayor riesgo y peor perfil epidemiológico está bajo la responsabilidad de los planes gubernamentales. El valor de la prima está excluido del cálculo de los rendimientos tributables de los empleados, y ni ellos ni los empleadores pagan impuestos sobre este monto.

En el Cuadro 2 puede observarse también el aumento del financiamiento público y la participación del Medicare al que le corresponde la quinta parte de los gastos. El Medicare está financiado por una combinación de impuestos sobre la planilla de pagos tributables de los trabajadores y empleadores y de pagos de primas por los beneficiarios. Según describían Skinner y colaboradores (9), para el año 2000 las diferencias en el nivel de gastos del Medicare entre los estados era notable. Si estos gastos se redujeran a los niveles de los estados con menores egresos, el desembolso global del Medicare disminuiría en alrededor del $30 \%$.

El Medicare Part A Trust Fund está financiado parcialmente por tasas federales aplicadas sobre las planillas de pagos (FICA taxes) de empleados y empleadores, en un porcentaje de $7,65 \%$ y $1,45 \%$, mientras que el restante es pagado por los propios beneficiarios. El Medicare Part $B$ es costeado por los ingresos generales en aproximadamente el $75 \%$, y por las primas mensuales de los beneficiarios en alrededor del $25 \%$.

El gobierno federal y los estados individualmente financian el Medicaid con un sistema en el cual los recursos estatales se recaudan de acuerdo a una tasa determinada por los niveles de renta de sus residentes. Cada estado diseña y administra su propio programa, lo cual resulta en una significativa variación en cobertura, beneficios y pagos. La participación federal varía de $50 \%$ a $83 \%$. Con pocas excepciones, el nivel

Cuadro 2. GASTOS EN CUIDADOS DE SALUD PERSONAL, DISTRIBUCIÓN PORCENTUAL SEGÚN FUENTES DE FINANCIAMIENTO

\begin{tabular}{l|rrrrrr}
\hline & $\mathbf{1 9 6 0}$ & $\mathbf{1 9 7 0}$ & $\mathbf{1 9 8 0}$ & $\mathbf{1 9 9 0}$ & $\mathbf{1 9 9 5}$ & $\mathbf{2 0 0 0}$ \\
\hline FONDOS PRIVADOS & 78,6 & 64,8 & 59,7 & 61,0 & 55,4 & 56,7 \\
COPARTICIPACIONES & 55,2 & 39,7 & 27,1 & 22,5 & 16,9 & 17,2 \\
SEGURO PRIVADO & 21,4 & 22,3 & 28,3 & 33,4 & 33,4 & 34,6 \\
OTROS & 2,0 & 2,8 & 4,3 & 5,0 & 5,1 & 5,0 \\
\hline FONDOS PÚBLICOS & 21,4 & 35,2 & 40,3 & 39,0 & 44,6 & 43,3 \\
FONDOS FEDERALES & 8,7 & 22,9 & 29,3 & 28,6 & 34,1 & 32,8 \\
\multicolumn{1}{c}{ Medicare } & - & 11,5 & 16,9 & 17,6 & 20,6 & 19,2 \\
OTROS & - & 4,3 & 6,4 & 6,6 & 9,5 & 9,8 \\
FONDOS LOCALES Y ESTATALES & 8,7 & 7,1 & 6,0 & 4,4 & 4,0 & 3,8 \\
\multicolumn{1}{c}{ Medicaid } & 12,6 & 12,3 & 11,1 & 10,5 & 10,5 & 10,5 \\
OTROS & - & 3,7 & 5,1 & 4,8 & 6,2 & 6,9 \\
& 12,6 & 8,6 & 5,9 & 5,6 & 4,3 & 3,6 \\
\hline
\end{tabular}

Fuente: Centros para los Servicios Medicare y Medicaid (CMS), en la OECD (2003) 
federal también paga la mitad de los costos administrativos del Medicaid. La contribución federal promedio es aproximadamente de $60 \%$ habiéndose modificado poco en la última década.

A pesar de que niños y adultos de familias de baja renta constituyen tres cuartos de la población cubierta por el Medicaid, el gasto está fuertemente concentrado en los programas para ancianos y discapacitados. Además de la cobertura de cuidados agudos y servicios preventivos, el Medicaid es el único organismo importante que paga cuidados crónicos o de larga evolución.

En los últimos años, los empleadores han reducido beneficios en la cobertura de medicamentos, han aumentado los co-pagos $(\mathrm{k})$ y realizaron deducciones en todos los tipos de planes, casi siempre para compartir costos con los usuarios, lo que se refleja en el aumento de los pagos directos. El objetivo es hacer participar al consumidor del servicio en el gasto, para hacerlo más consciente de los costos involucrados en el cuidado, tornándolo costo-efectivo. Este aumento en la coparticipación de los pacientes se debe a los riesgos morales que implican para él mismo tomar decisiones relativas al consumo de servicios de salud utilizando recursos de terceros.

En el Cuadro 3 puede verse la participación de los ítems más representativos en los gastos de salud, que son los cuidados hospitalarios, los servicios médicos, clínicos y los medicamentos. Estos últimos, a su vez, constituyen el gasto que más se ha incrementado en las últimas décadas.

\section{LA REFORMA DEL SISTEMA DE SALUD ESTADOUNIDENSE EN LOS AÑOS ‘90}

En esta sección se describe y analiza la reforma del sistema de salud estadounidense en los años '90, y las dos Leyes Federales más importantes promulgadas en ese período: la Health Insurance Portability and Accountability Act (HIPAA), de 1996, y la Balanced Budget Act (BBA), de 1997. Inicialmente describimos el contexto en el cual se dieron los cambios implementados por el gobierno federal. Luego se analizan sus objetivos y las acciones adoptadas.

CUadro 3. GASTOS EN SALUD PERSONAL Y NO PERSONAL, DISTRIBUCIÓN PORCENTUAL POR TIPO DE SERVICIO.

\begin{tabular}{l|rrrrrr}
\hline & $\mathbf{1 9 6 0}$ & $\mathbf{1 9 7 0}$ & $\mathbf{1 9 8 0}$ & $\mathbf{1 9 9 0}$ & $\mathbf{1 9 9 5}$ & $\mathbf{2 0 0 0}$ \\
\hline CUIDADOS DE SALUD PERSONAL & $\mathbf{8 7 , 6}$ & $\mathbf{8 6 , 5}$ & $\mathbf{8 7 , 3}$ & $\mathbf{8 7 , 6}$ & $\mathbf{8 7 , 4}$ & $\mathbf{8 7 , 0}$ \\
Cuidado hospitalario & 34,4 & 37,8 & 41,3 & 36,5 & 34,7 & 31,7 \\
Servicios médico y clínico & 20,1 & 19,1 & 19,2 & 22,6 & 22,3 & 22,0 \\
Servicios odontológicos & 7,4 & 6,4 & 5,4 & 4,5 & 4,5 & 4,6 \\
Otros servicios médicos & 1,5 & 1,0 & 1,5 & 2,6 & 2,9 & 3,0 \\
Cuidados de salud domiciliarios & 0,2 & 0,3 & 1,0 & 1,8 & 3,1 & 2,5 \\
Productos médicos no durables & 6,1 & 4,6 & 4,0 & 3,2 & 2,6 & 2,4 \\
Prescripción de medicamentos/drogas & 10,0 & 7,5 & 4,9 & 5,8 & 6,1 & 9,4 \\
Equipo médico durable & 2,4 & 2,3 & 1,6 & 1,5 & 1,4 & 1,4 \\
Cuidado en casa de reposo & 3,2 & 5,8 & 7,2 & 7,6 & 7,5 & 7,1 \\
Otros cuidados personales & 2,4 & 1,7 & 1,3 & 1,4 & 2,3 & 2,8 \\
\hline CuIDADOS DE SALUD NO PERSONAL & & & & & & \\
Administración y costo neto privado seguro de salud & $\mathbf{1 2 , 4}$ & $\mathbf{1 3 , 5}$ & $\mathbf{1 2 , 7}$ & $\mathbf{1 2 , 4}$ & $\mathbf{1 2 , 6}$ & $\mathbf{1 3 , 0}$ \\
Actividad de salud pública gubernamental & 4,5 & 3,8 & 4,9 & 5,7 & 6,1 & 6,2 \\
Investigación & 1,5 & 1,9 & 2,7 & 2,9 & 3,2 & 3,4 \\
Construcciones & 2,6 & 2,7 & 2,2 & 1,8 & 1,7 & 2,0 \\
\hline
\end{tabular}

Fuente: Centros para los Servicios Medicare y Medicaid (CMS), en la OECD (2003) 


\subsection{EL CONTEXTO}

La reforma sanitaria estadounidense de los años '90 se desarrolló en un contexto que presentó cuatro aspectos de importancia: un amplio movimiento y una fuerte sensibilidad alrededor de los derechos del paciente; el problema del aumento de la población no asegurada; la presión del aumento de los gastos en salud sobre la economía; y la propuesta Clinton de reforma sanitaria 1993/1994, que fue rechazada por el Congreso norteamericano.

Los años '90 fueron un período de mayor consideración hacia los derechos del paciente y de retroceso del Managed Care. A principios de la década, los empleadores utilizaron la modalidad del Managed Care para controlar el rápido aumento de los costos en salud. Las estrategias de limitación de elección de prestadores por parte de los pacientes, la intervención de los gestores en las decisiones médicas y la contratación selectiva de proveedores alternativos condujeron a una gran insatisfacción y a una reacción contra las características más restrictivas del Managed Care.

La continua presión política ejercida hasta mediados de los años '90 obligó a muchos estados a aprobar leyes reconociendo los derechos de los pacientes con requerimiento de coberturas especiales, estableciendo jornadas hospitalarias en ciertas condiciones y más adelante, otros derechos del prestador. A nivel nacional, el Congreso debatió una ley para establecer ciertos derechos de los pacientes. El asunto que generó un obstáculo en el Congreso fue aquel relacionado a la extensión de los daños que el paciente puede recibir si un plan, equivocadamente, niega cobertura (8). La noción de derechos de los pacientes persiste como una causa políticamente popular.

Un marco importante para la protección de los derechos del consumidor fue el nombramiento de la Advisory Commission on Consumer Protection and Quality in the Health Care Industry, en 1997. Esta comisión tenía por objetivo: informar al presidente sobre los cambios en el sistema, recomendar medidas para asegurar la calidad en los cuidados, y valorizar y proteger a consumidores y trabajadores. En marzo de 1998 fue presentado el documento final Consumer Bill of Rights and Responsabilities, con recomendaciones en ocho áreas de derechos y responsabilidades del consumidor.

Muchos proveedores, incluyendo el gobierno federal, han incorporado a sus planes de salud algunas de las prestaciones propuestas por el Congreso. Esto hizo que las mejoras se extendieran a más personas, pero la tensión solamente se redujo al introducir los cambios en los planes de gestión más restrictivos.

A comienzos de la década del '90, el problema de los no asegurados constituía otro ítem importante en la agenda de salud. A pesar de las acciones para promover mayor competencia entre prestadores y planes de salud en los años '80 e inicio de los años '90, la población no asegurada creció continuamente durante ese período: de 30 millones de personas en 1980 aumentó hasta alcanzar un pico de 34 millones en 1995.

El tercer aspecto importante al inicio de los años '90 era el comportamiento de los gastos y los costos en salud. Los años '80 fueron especialmente preocupantes desde el punto de vista del crecimiento de los gastos reales y de los precios de los cuidados individuales en salud. Las estimaciones para los años siguientes tampoco eran alentadoras.

Finalmente, el aspecto más importante en el contexto de las reformas de los años '90 fue la propuesta enviada por el presidente Clinton al Congreso en octubre de 1993, el Health Security Act (HSA). Durante la campaña, Clinton había prometido una reforma del sistema de cuidados de salud, pero su propuesta colapsó en 1994. Los principales puntos del HSA eran:

1. cobertura universal;

2. beneficios uniformes y comprehensivos;

3. creación de las Health Alliances (I);

4. principio del mandato del empleador $(\mathrm{m})$;

5. libre elección universal;

6. oferta de los planes de salud en las Alianzas regionales;

7. principio del mandato único de las Alianzas.

El HSA proponía una reorganización profunda en el sistema de salud que establecía, entre otras cosas, la universalidad del acceso a los cuidados de salud. Esta reorganización estaba 
apoyada en los principios de la managed competition, que buscaba estimular la competencia entre las alianzas regionales, los planes y los proveedores de salud; imponía a los empleadores la obligatoriedad de aportar como mínimo el $80 \%$ de las primas de los seguros de sus funcionarios; y otorgaba a las Alianzas de Salud un poder monopólico para la contratación centralizada de los servicios de salud o de un plan para asegurar la cobertura de sus afiliados. Habría sólo una Alianza regional por área, y todos los grupos con menos de 5.000 empleados estarían obligados a buscar cobertura en aquella alianza.

La coyuntura de finales de 1993 y principio de 1994 era favorable a la aprobación del HSA por el Congreso. La opinión pública acompañaba el debate y era favorable a las reformas y al Plan Clinton. Un estudio revelaba que el $82 \%$ de la población apoyaba las reformas específicas y que el $43 \%$ apoyaba todo el Plan. Los cuidados de la salud y la reforma del sistema era el segundo tema de mayor interés, después de la economía. Se estima que al momento del discurso presidencial, la noche del 22 de septiembre de 1993, el 78\% de la población percibía que su sistema de salud no atendía a la mayoría de la población (11).

El año 1994 era de elecciones para el Congreso, y de renovación de un tercio del Senado. La oposición republicana se preocupaba por mostrar una postura responsable y constructiva con relación al Plan, evitando ataques más agresivos. El Partido Demócrata y el presidente Clinton también comenzaron con una ventaja especial: solamente en cuatro ocasiones, en los últimos 50 años, el ocupante de la Casa Blanca era del partido que controlaba el Senado y la Cámara baja.

El Presidente demostró desde el inicio su compromiso con la reforma de la salud, y su portavoz en la comunidad médica afirmó que todo era negociable. Un grupo de republicanos, la mayor parte moderada, que presentó un plan con similitudes al de Clinton pero con diferencias en cuanto al financiamiento, reconocía también la necesidad de cuidados universales y que el gobierno debía determinar el paquete mínimo de beneficios.

Otras señales positivas eran que dos grupos poderosos apoyaban el Plan: la Asociación Americana de Jubilados, con 32 millones de miembros, y la Federación Americana del Trabajo y Congreso Industrial de Organizaciones, con 14 millones. Los pequeños empresarios y el sector de seguros rechazaban la propuesta, y grupos como AMA mantuvieron una oposición cautelosa.

Si el Plan Clinton contaba con apoyo público para la reforma, un Congreso dominado por el mismo partido y muchos de los potenciales opositores con miedo de reacción, ¿por qué no fue aprobado por el Congreso?

Había importantes intereses contra el Plan Clinton. Más de 1.100 asociaciones relacionadas con los cuidados de la salud se verían afectadas. Centenas de aseguradoras de salud estarían forzadas a salir del mercado, expulsadas por las HMOs y por las redes prestadoras. Se estimaba que de las más de 500 compañías de seguros, sólo 5 ó 6 grandes sobrevivirían. Tampoco habría lugar para los agentes de seguro con el funcionamiento de las Alianzas. Los pequeños empresarios, a su vez, también serían perjudicados porque estarían obligados a costear el $80 \%$ de los gastos en salud de cada empleado, y se estimaba que muchos pequeños empresarios quebrarían. Según algunos informes, la administración reconocía que en los 5 años siguientes a la implantación del nuevo sistema, más de 200 mil personas perderían sus empleos (12).

El Plan, que fue presentado como algo simple, tenía 1.342 páginas y era en realidad bastante complejo. Contemplaba la creación de 59 nuevos programas y agencias federales, la expansión de 20 órganos, se imponía a más de 75 mandatos federales y requería modificaciones del Código Tributario (13). Según Rothschild (14), el Plan colocaría 14\% más de la economía norteamericana bajo el control de los burócratas federales.

Muchos puntos del Plan eran observados como poco claros. Robbins (15) cita, por ejemplo, la creación de dos nuevas burocracias complejas, las Regional Alliances y el National Health Board; que la reducción de gastos privilegiaría sólo a la parte correspondiente al gobierno federal, que caería del $52 \%$ hasta el $43 \%$ en 2005 ; que no debería ocurrir la reducción de precios por la managed competition; y que no estaban claras las nuevas fuentes de financiamiento. Cuneo (12) y Goldsmith (10) interrogaban sobre las formas de financiamiento del Plan. El presidente no había discutido ese punto ni con el Congreso ni con la población. La administración calculó que el Plan costaría US\$ 100 mil millones, pero se basaba en 
importantes ahorros en el Medicare y Medicaid, que muchos demócratas criticaban. La creación de impuestos sobre cigarros y bebidas, además de difícil, probablemente no cubriría los gastos adicionales. El resultado fue un plan principalmente costeado por un seudo-impuesto, el mandato del empleador, cuya fuente era el subsidio de US\$ 60 mil millones en impuestos federales, en seguro de salud provisto por el empleador, que sería retirado después de 10 años. Los republicanos veían este financiamiento como inaceptable, porque recaía sobre los pequeños empresarios y firmas con muchos empleados sin cobertura, y porque se gastarían más dólares donde ya existía una mayor cobertura.

Las Alianzas Regionales causaban un gran temor, y un seguro nacional de salud no era factible en los EE.UU. Según Goldsmith (10), a pesar de estas limitaciones, lo que imposibilitó el Plan Clinton no fue la intransigencia republicana, sino la falla en movilizar a los moderados de su propio partido. Esta propuesta (16) preocupaba en varios aspectos:

1. La exigencia que obligaba a los planes a contratar o reembolsar a sus prestadores principales durante los primeros cinco años de programa, imposibilitándolos de contratarlos sólo por la utilización de los servicios.

2. La fluctuación en el número de afiliaciones, especialmente al principio, podría crear problemas.

3. El control de costos por medio de techos de primas y tablas de honorarios no era coherente con el espíritu de competencia y libre elección del consumidor.

4. La inclusión del Medicaid en las Alianzas regionales. EL HSA proponía pagar los planes al $95 \%$ de lo que Medicaid pagaba. Como Medicaid ya pagaba menos que el costo en la mayor parte de los estados, los planes que tuvieran una mayor parte de esos beneficiarios estarían en desventaja y hasta en desequilibrio. Adicionalmente, las alianzas corporativas no tendrían responsabilidad sobre el Medicaid, y la tasa del $1 \%$ sobre la prima que ellas deberían pagar a la Alianza Regional no cubriría los costos del Medicaid.

5. Las HMOs debían ofrecer la opción del plan point-of-service, facilitando los cambios de planes, sin restricción a la elección de médicos aunque limitada para otros servicios. Sin embargo, este beneficio era muy diferente a los planes point-of-service corrientes, ya que no contemplaba una posibilidad de deducción por cubrir todos los servicios y requería un $40 \%$ de co-seguro para el usuario.

6. El número de 5.000 personas para componer las Alianzas regionales sería inicialmente muy grande. Una propuesta con grupos más pequeños, de 100 hasta 200 empleados para el comienzo, hubiera despertado un menor rechazo.

Según Landau (17), la reforma no funcionó porque el Presidente perdió más tiempo modificando la propuesta que negociando, retrasándola en el Congreso y perdiendo el apoyo público. Para asegurar el apoyo, nuevos beneficios fueron ofrecidos a los constituyentes demócratas: beneficios de jubilación federalizados después de los 55 años para trabajadores sindicalizados; una nueva cobertura de drogas y eventualmente cuidado crónico para ancianos; atención de salud mental en el paquete básico; y otros (10).

Para Rothschild (14), el Plan diseñado por Hillary Clinton e Ira Magaziner, coordinadora de la Comisión de Cuidados de Salud, reflejaba el pensamiento clásico de la edad de las máquinas: centralizaba decisiones por medio del poder monopolista, aseguraba estabilidad por medio de controles rigurosos, insistía en un estándar de tamaño único, planificaba de antemano hasta los mínimos detalles y no abría espacio para la innovación.

Gabel (18), en una investigación sobre el seguro de salud de EE.UU. en 1993, concluyó que aunque la reforma no fuera aprobada, continuando los cambios corrientes, en el futuro el sistema de salud no contrastaría mucho con el imperante décadas atrás. El fracaso de la reforma dejó un clima de ansiedad y la sensación de que algo debía hacerse. Landau (17) predijo que la reforma sería nuevamente colocada en la agenda nacional en la forma de "los niños primero" y en reformas estado por estado.

\subsection{LAS INICIATIVAS DE REFORMA}

En agosto de 1996, el Congreso aprobó el Health Insurance Portability and Accountability Act (HIPAA). Su intención principal era proteger la cobertura del seguro de salud para trabajadores 
y sus familias cuando perdían o cambiaban sus empleos, estableciendo modelos de mantenimiento de la protección. Reconociendo que esta nueva protección impondría una carga administrativa adicional a los proveedores de cuidados, pagadores y otros, la ley incluyó una sección que pretendía promover la transparencia electrónica de información en salud entre organizaciones, para aumentar la eficiencia y el costo-efectividad del sistema de cuidados.

La medida permitió a los trabajadores asegurados elegibles (que presentan ciertas condiciones) mantener su cobertura aunque dejasen sus empleos y eliminó el rechazo de cobertura para aquellos con condiciones preexistentes (riesgos o patologías). También estableció un programa de cobertura de enfermedades catastróficas para empleados de pequeñas empresas, los trabajadores por cuenta propia y los no asegurados.

El HIPAA afectó más al mercado de pequeños grupos que al mercado individual, porque estableció requisitos de acceso al seguro con reglas de determinación de primas y su disponibilidad. Sin embargo, el limitado alcance de la ley no disminuyó los 40 millones de no asegurados. La aprobación del HIPAA se dio en medio de un discurso por parte de la Casa Blanca, donde se decía que había más por hacerse y que se estaba realizando un importante paso incremental.

El Congreso aprobó en agosto de 1997, los proyectos de ley Balanced Budget Act (BBA) y Taxpayer Relief Act. Esta iniciativa buscaba mantener los gastos federales bajo control. Con la primera ley se pretendía efectuar recortes de US\$ 198 mil millones en los gastos federales en el período 1998-2002. La segunda ley buscaba realizar recortes de US\$80 mil millones en impuestos (19).

Los recortes previstos por el BBA 1997 en los gastos federales en salud apuntaron al Medicaid y fundamentalmente al Medicare, ante el inminente riesgo de quiebra en 2001 y con la expectativa de mantener su equilibrio hasta 2007 $(20,21)$. Para los 5 años siguientes se calculaba una reducción de gastos de US\$112 mil millones en el Medicare, basada en una disminución de US\$ 98,6 mil millones en pagos de beneficios (incluyendo US\$44 mil millones en los pagos a hospitales y US\$ 9 mil millones en cuidados hospitalarios, domiciliarios y servicios calificados de enfermería), y un aumento de las primas en US\$13,4 mil millones. En cuanto al Medicaid, el recorte proyectado era de US\$ 7,2 mil millones para el mismo período.

Las principales acciones impulsadas por el BBA 1997 fueron: la creación de Medicare+Choice Program; la implementación de medidas para combatir los fraudes y el abuso en los dos programas (n), y la introducción de un nuevo sistema de pagos, el Prospective Payment System (PPS) para pagos en las partes A y B del Medicare. Además, promovió una disminución del uso de los servicios de cuidado domiciliario y creó los Programs of All-Inclusive Care for the Elderly (PACE) para extender los cuidados de enfermería a individuos con 55 años o más, y el State Children's Health Insurance Program (SCHIP) para aumentar la cobertura de niños no asegurados. Analizamos a continuación los aspectos más importantes.

El Medicare+ Choice Program fue creado en base a un programa existente que permitía la participación en el Medicare sólo a las HMOs. El programa + Choice abrió la posibilidad de inclusión a las preferred provided organizations y a otros tipos de planes de Managed Care, como planes fee-for-service de administración privada y de algunas organizaciones médicas con condiciones determinadas.

Los planes + Choice ofrecen un paquete de beneficios ligeramente más amplio que el programa tradicional. En esta modalidad, los planes privados reciben reembolsos por el $95 \%$ del costo del tratamiento de un afiliado común del Medicare, en el mismo condado, en el sistema fee-for-service (o). El valor reintegrado es del $95 \%$ porque se considera que con el Managed Care se podría y se debería ahorrar algún recurso.

El BBA 1997 también estableció nuevos sistemas de pagos prospectivos en el Medicare (p), que posteriormente fueron utilizados con las agencias de salud domiciliaria, atención ambulatoria y cuidados de enfermería en domicilio. El nuevo sistema de pagos prospectivos (PPS) fue implantado en las partes A y B del Medicare y está basado en tasas fijadas en forma prospectiva para cada prestación, calculadas sobre un promedio 
nacional ajustado y normalizado por varios factores, como la renta y la ubicación. Después de un primer año (1997) de mantenimiento en los niveles de gastos se preveía obtener reducciones para los principales ítems del Medicare durante el período 1998-2002.

El Medicare, que históricamente reembolsaba $90 \%$ de los costos de los servicios ambulatorios, después de la aprobación del BBA 1997 vendría a remunerar $82 \%$, y después de la implantación del PPS para los cuidados ambulatorios se reduciría a 78\% (22). Por primera vez se introducía un sistema de pagos prospectivos para servicios de internación y de cuidado domiciliario de enfermería.

El BBA 1997 estipuló topes máximos para gastos no restringidos, y por primera vez los hospitales recibirían una tasa menor de reembolso por pacientes derivados para cuidados postagudos. A pesar de las críticas de la Asociación de Hospitales Americanos, que argumentaba que esto penalizaría a los hospitales, que se verían obligados a reducir los tiempos de permanencia para mejorar su eficiencia, la HCFA entendía que se trataba de una buena política, dada la elevada proporción de pacientes Medicare admitidos para cuidados post-agudos después de haber recibido cuidados agudos.

También fueron definidas previsiones de impacto en el financiamiento, incluso de programas de graduación médica, estableciendo un techo nacional de puestos de residencia en el Medicare, una reducción progresiva de cinco años en el cálculo del apoyo indirecto de educación médica, la reducción en pagos para hospitales de servicios de internación y otros.

Finalmente, se creó el SCHIP para extender la cobertura de los niños sin seguro. Bajo este programa, los estados obtienen financiamiento federal con una alta tasa de contrapartida. Según Bergen (1997), en un histórico compromiso, con una inversión de US\$ 24 mil millones al año, sería efectuada la más grande expansión del programa de salud del niño desde la concepción del Medicaid, incorporando a la cobertura a más de dos millones de niños en todo el país.

EI BBA 1997 fue adecuado en muchos aspectos. Contenía, además, algunas de las propuestas del HSA de Clinton, pero también fue muy duro, y ocasionó los más grandes cambios en el Medicare desde la concepción del programa en 1965 (23). Las medidas ejecutadas tuvieron consecuencias no previstas en el BBA 1997, que cuadruplicaron y más el impacto de los recortes, aumentando las reducciones en los gastos de los programas de US\$ 16,2 miles de millones previstos a más de US\$70 mil millones en los primeros cinco años del nuevo sistema (24). Según el GHA (23), el recorte esperado en el sector hospitalario, de US\$ 44 mil millones al momento de la aprobación de la ley, fue recalculado en US\$ 76,6 mil millones. El BBA 1997 tuvo efectos colaterales que traumatizaron la industria y ocasionaron serias distorsiones (25). Además, Craig (20) aún mostraba que el HCFA no era capaz de implementar las reformas del BBA 1997 en la manera y el tiempo adecuados.

En virtud de la intensidad de los recortes previstos y no previstos, de las reacciones opuestas de los prestadores de servicios al Medicare y de la disminución del interés por la afiliación al Medicare + Choice, lo que se tradujo en clausura de camas y de servicios en salud, en 1999 fue aprobado el Budget Refinement Act (BBRA) y en el 2000, el Benefits Improvement and Protection Act (BIPA), que pretendían reducir algunos de los efectos negativos del BBA. De una forma general, el BBRA 1999 y el BIPA 2000 prorrogaron plazos del BBA 1997, establecieron excepcionalidades y alteraron parámetros y cálculos.

EI BBRA restablecería un monto de US\$ 17 mil millones de los recortes en el Medicare estimados para los 5 años siguientes y aproximadamente US\$ 8,4 mil millones para los hospitales. Estos valores corresponden a menos del $10 \%$ de los recortes originales. La mayor parte de su recomposición se da por la naturaleza transicional de los hospitales rurales, de los establecimientos de cuidados especializados de enfermería y de los cuidados ambulatorios.

Entre los elementos más importantes del BBRA 1999 se destacan:

1. El $20 \%$ de aumento para 15 de los Grupos de Utilización de Recursos (RUG) (q) que permanecerían hasta afinar la reclasificación del mix de casos RUG. Una vez completado el refinamiento, los pagos del Medicare a los establecimientos de enfermería especializada serían reducidos en US\$1.000 millones al año. 
2. El aumento temporal de $4 \%$ en el pago de la cuota federal de la tasa de ajuste diario, prevista para durar dos años y medio, estimada en US\$ 600 millones al año (26).

El BIPA 2000 fue aprobado en diciembre de 2000 y contiene muchas previsiones afectando políticas de pagos de internaciones, con varias fechas para entrar en vigor. EI BIPA 2000 proporcionó cambios en el presupuesto federal del 2001 para pagos de internaciones; beneficios a hospitales comunitarios, centros de referencia rurales y otros pequeños hospitales urbanos $y$ rurales; pequeños hospitales rurales dependientes del Medicare; revisión de los montos de los pagos PPS; educación medica indirecta; disminución de las reducciones de los pagos a grandes hospitales; extensión de la reclasificación de pagos; aumento del incentivo pagado a hospitales y unidades psiquiátricas excluidas; aumento en el recurso ajustado en $75 \%$ del techo para pagos a hospitales de cuidados crónicos; y aumento en el reembolso para débitos mal efectuados de hospitales (27).

El BIPA 2000 proporcionó un aumento del $16,7 \%$ al componente de enfermería, con una duración temporal de 18 meses y un valor anual estimado de US\$ 1,1 mil millones; $6,7 \%$ de aumento en 14 pagos de RUG para servicios de rehabilitación; y la eliminación del índice de reducción en 1\% del Market Basket por el BBA 1997.

\subsection{RESULTADOS}

El sistema sanitario norteamericano vivió tres momentos clave durante la década del '90: el intento de reforma de 1992, que fue abortada por el Congreso en 1994; las reformas de 1996 y 1997, orientadas a la ampliación del acceso y el control de gastos; y las contrarreformas de 1999 y 2000, que buscaban atenuar los elevados controles y los rígidos techos de gastos establecidos por el BBA 1997.

Pero después de estos tres momentos, todos durante la gestión Clinton (1992-2000), ¿cuál fue el resultado de esta década de reformas? Inicialmente analizamos el impacto de las reformas en función de los gastos en salud y de los programas gubernamentales Medicare y Medicaid. Posteriormente, analizaremos la cobertura y el acceso a los cuidados.
Los gastos en salud realmente tuvieron un aumento menor entre 1993 y 2000 (29,7\%). El porcentaje es elevado pero inferior, a cálculo anualizado, al de los periodos 1988/1993 y 2000/2003, cuando tuvieron un crecimiento real de $35,7 \%$ y $20,3 \%$ respectivamente. El componente fármacos es el ítem que más creció y los factores de ese aumento son: desarrollo de nuevos medicamentos, preferencia por el tratamiento con drogas; anuncios que estimulan la demanda; y la cobertura por los planes, excepto Medicare. En el año 2000, el 68\% de los recursos de prescripción eran cubiertos por el seguro, en oposición al 41\% de 1990.

Las reformas de mediados de los años '90 fueron temporalmente exitosas en la contención de gastos de Medicare. Este programa presentó un crecimiento no sustentable de cerca del 9\% anual entre 1993 y 1996, y se creía que eso continuaría. El BBA 1997 buscaba reducir ese crecimiento. Antes de ser aprobado, el Congressional Budget Office estimaba que los gastos del Medicare crecerían 5,8\% después de 2002, y 7,2\% después de 2007. Luego ya se calculaba en 4,5\% al año en los cinco años siguientes, y 6,5\% en los próximos diez años. Los gastos del Medicare en la segunda mitad de la década del '90 decayeron para luego volver a crecer más lentamente. Esto contribuyó a que el costo total del Medicaid y del SCHI se aproximaran al del Medicare.

En 2001, el 86\% de los beneficiarios del Medicare estaban cubiertos por el programa tradicional y el resto estaba matriculado en el + Choice (7). El + Choice falló en Ilamar la atención de las HMOs para que participaran del negocio. En los tres primeros años del programa, el total de beneficiarios aumentó progresivamente hasta finales de 1999, cuando alcanzó el máximo de 6,3 millones. Dos años después se redujo a 5,5 millones, el mismo número de 1997. Esta iniciativa falló en atraer nuevos planes de salud y muchos se retiraron o restringieron su participación, reduciendo beneficios o incrementando coparticipaciones. El Medicare ha ofrecido pagos poco atractivos en ciertas localidades, y exige que los planes participantes divulguen información sobre la calidad de servicios y performance (desempeño), adicionando costos.

Los resultados financieros del + Choice son cuestionables. Sus planes cuentan con beneficiarios más saludables que el promedio del 
Medicare, lo que no se refleja en primas más bajas. Además, sus costos administrativos varían ampliamente, del $3 \%$ al 32\%, con ítems extraños, lo que da como resultado US\$ 1.000 millones anuales en sobrepagos. Una vez que los planes + Choice son remunerados de acuerdo con el $95 \%$ del promedio de los pagos FFS Medicare, también son beneficiados con el costo del fraude y de los abusos de aquel sistema. De acuerdo con Stark (28), esto ocasiona una pérdida de $7 \%$ del gasto total.

El resultado de los cambios en el Medicare, y la rapidez con que ocurrieron, también generó protestas por parte de los prestadores y de los planes de salud, por el creciente número de requerimientos regulatorios modificables y complicados.

Con respecto a Medicaid, los aumentos presupuestarios estatales animaron una renovada expansión del programa en 1999, pero que debió enfrentar problemas debido a la falta de robustez de la economía y a la escalada de los costos en salud. Como respuesta, los estados controlaron sus gastos, con medidas como el corte de pagos a prestadores y la revisión de los criterios de elegibilidad. Se estima que las matrículas en 2001 han excedido los niveles de mediados de los años '90, y se esperan significativas presiones a los programas estatales dedicados al cuidado crónico de ancianos y discapacitados (7).

Con respecto al total de asegurados, en el 2000 el número fue superior al de 1990, pero inferior al de 1980. Esto se debió a diversos factores, como un pobre desempeño de la economía, la reducción en la cobertura de los empleadores y la incapacidad de las políticas públicas para incorporar más personas. El impacto de la reforma en cuanto a ampliar la cobertura fue muy pequeño, restringido a dos pequeños grupos de la población no asegurada: los niños de familias con baja renta y las personas en riesgo de perder el seguro. En el primer caso, hubo una baja tasa de incorporación, a pesar de que más de tres cuartas partes de todos los niños no asegurados son elegibles para la cobertura ofrecida por el Medicaid o el SCHIP (7).

Después del período de relativo pequeño crecimiento al final de los años ' 90 , las primas correspondientes al empleador volvieron a crecer en 2001, alcanzando el $11 \%$. Desde entonces, su crecimiento fue acelerándose, hasta aproximarse a los niveles de los años '80 (15\% a 20\% anuales). Este aumento es consecuencia del ciclo de seguro-salud, del crecimiento en los costos periféricos y del aumento de la rentabilidad de los planes. En 2002, los empleadores contribuyeron con el $15 \%$ en promedio del costo de cobertura individual y $27 \%$ para la cobertura familiar (7).

La primera mitad de los años '90 fue un período de rápida expansión del Managed Care, que vio perder su atractivo al final de la década. Un reflejo de este crecimiento puede percibirse en la sustitución del fee-for-service por el GRD. La modalidad fee-for-service, dominante en el inicio de los años '90, cayó al 27\% en 1996 y llegó al 7 \% en 2001 (7).

La retracción del Managed Care y la valorización de los derechos de los pacientes hicieron que las aseguradoras ofrecieran nuevos productos con pocos controles, redes más extensas y mayor cobertura fuera de la red. Los actores-clave se han adaptado a los cambios de financiamiento, organización y provisión de servicios. El número de HMOs cayó 9,4\% de 2001 a 2002, año en que se contabilizaban 490 unidades. La previsión para 2004 era que Ilegaran a 425, con una caída de $25 \%$ frente a las 570 existentes en 1995. En 2001 las preferred provided organizations reunían al $48 \%$ de los trabajadores, contra el 28\% de 1996. Los planes point of service, que permiten recibir atención fuera de la red bajo diferentes arreglos de cost-sharing, aumentaron su mercado de $14 \%$ a $22 \%$ en ese período. Esos planes reemplazaron a las HMOs como forma predominante.

Finalmente, durante los años '90 hubo una concentración del sector en un número menor de prestadores de servicios, y un aumento en los costos de administración del sistema. El número de hospitales cayó un 14\% durante la década, la mayor parte hospitales comunitarios, dos tercios de ellos privados sin fines de lucro. La reducción del número de hospitales fue acompañada de una reducción del número de camas, de $4,9 \%$ en 1990 a 3,6\% en 2000, uno de los menores en los países de la OECD. Esta disminución de la oferta de servicios se explica por los siguientes factores:

1. el sistema de pagos prospectivos del Medicare creó incentivos para la reducción en el tiempo de estadía hospitalaria; 
2. los esfuerzos de contención de costos por los planes Managed Care llevaron a fusiones, para reducir costos y recuperar poder de mercado;

3. la reducción en los márgenes de las prestadoras de servicios.

En la disputa entre los terceros pagadores y los prestadores de salud, los primeros salieron claramente ganando. En 2002, las primas comerciales promedio aumentaron $14 \%$, contra un aumento de costos de $12,8 \%$. La ganancia promedio de las compañías Managed Care fue de 4,4\% en 2002, comparada a 1,8\% de 1999.

\section{CONCLUSIÓN}

En esta última sección analizamos las reformas como un gran movimiento que perduró por casi una década y que transcurrió durante una única gestión: la del presidente Clinton. Inicialmente, comentamos cómo fueron relacionándose las reformas entre sí. Luego, describimos la influencia de estas acciones sobre el modelo de cuidado de la salud norteamericana. En tercer lugar, mostramos la evolución de los gastos en ese período y buscamos identificar cuáles fueron los principales aspectos que podrían explicar esa tendencia. Finalmente, estudiamos el impacto sobre la cobertura y el acceso a los servicios en función de los cambios impuestos por las reformas.

Las reformas en el sistema de salud estadounidense de los años '90 no se realizaron en base a un modelo homogéneo, no fueron coherentes ni continuas. El proyecto Clinton de 1992 pretendía la universalización del acceso a los cuidados de salud, y estaba basado en la managed competition y en la construcción de un modelo centralizado de compra de servicios. Proponía una modificación profunda del modelo sanitario, próximo al Pluralismo Estructurado descripto por Londoño y Frenk (2). Las propuestas de 1996 y 1997 fueron focalizadas:

1. la primera buscaba la ampliación de la cobertura, incorporando dos grupos menores al sistema de cuidados;

2. la reforma de 1997 fue eminentemente económica y estuvo dirigida a los planes guberna- mentales, buscaba reducir las transferencias a prestadores y terceros pagadores, y a establecer techos de gastos.

Las reformas de 1999 y 2000 deshicieron en parte lo establecido por el BBA 1997, reduciendo significativamente el ajuste financiero. Los factores que incidieron fueron la presión de varios grupos del sector salud, la necesidad política de mantener un elevado déficit fiscal debido a las elecciones del 2000 y la perspectiva de desafiliación de prestadores y aseguradoras afiliadas a los planes gubernamentales, debido a la reducción en el financiamiento de los servicios.

Los años '90 no trajeron modificaciones importantes en el diseño del modelo sanitario, que conservó las características del Modelo Privado Atomizado descrito por Londoño y Frenk (2). Los intentos de limitación de gastos, la imposición de nuevos controles y el establecimiento de un nuevo marco regulador no mejoraron el sistema; al contrario, lo hicieron aún más pesado, complejo y caro. Los costos administrativos aumentaron en términos reales desde los años '70 y hoy son el quinto ítem más importante en los gastos en salud. La expansión del managed care produjo un incremento de la rentabilidad de los terceros pagadores, y una reducción y centralización de la red prestadora de servicios.

Los gastos en salud aumentaron en tasas menores al final de los años '90, pero siempre por encima de la inflación, del crecimiento de la economía y del promedio de los países de la OCDE. Su evolución volvió a ser preocupante en los últimos años, y las estimaciones para los próximos años alcanzan a los US\$ 3 billones, lo que equivale al $17 \%$ del $\mathrm{PBI}$ norteamericano en 2012. Todos los ítems de gastos aumentaron: los pagos directos, los gastos correspondientes a seguros privados y los gastos públicos.

La relajación de los controles de gastos que promovieron las reformas de 1999 y 2000, más la coyuntura política, contribuyeron a un nuevo crecimiento de los gastos. Sin embargo, no hay consenso con respecto a cuáles son los factores responsables de este comportamiento, y tampoco hay acuerdo en cuanto a lo que debería hacerse. Según Altman (29) y otros, la sociedad americana quiere consumir más servicios de salud, y por lo tanto gasta más. Para Pauly (30), 
los gastos siguen un ciclo influenciado por los márgenes de lucro de los prestadores y por el crecimiento de la economía. Varios análisis destacan los elementos tecnológicos y de práctica médica como factores determinantes (8). Otros evalúan que es un reflejo retardado de las alteraciones del PBI norteamericano, hay quienes proponen mayor competencia entre los prestadores y están los que defienden una mayor regulación.

Finalmente, las acciones de la reforma de 1996 mejoraron la cobertura del sistema, incorporando a grupos antes marginados. Sin embargo, esto no influyó mayormente sobre el número de los no asegurados. En ese sentido, el número de asegurados al final de la década del '90 fue menor que al principio de la misma, aunque por encima del récord negativo de 1995. Manteniendo el diseño actual de sistema, con las mismas restricciones presupuestarias e igual perspectiva política sobre el problema de los no asegurados, se estima que el crecimiento de la economía norteamericana sería el elemento que más podría influir sobre el acceso de la población a los servicios de salud.

La cobertura acabó siendo más cara y precaria en los años '90 debido a la introducción y la ampliación de las coparticipaciones, co-seguros y deducciones, y la expansión del managed care, que introdujo mayores limitaciones al consumo y a la libre elección de médicos y proveedores. La mejor consideración hacia los derechos de los pacientes y el retroceso del managed care al final de los años ' 90 , deben haber mejorado un poco estas condiciones.

Después de una década de reformas, la sensación es de retorno al punto de partida de 1992. La reforma de los años '90 implicó la introducción de elementos de gerencia innovadores.
Estos mecanismos fueron implantados según una lógica competitiva y de mercado, con un enfoque macroeconómico. Ocasionaron un aumento de los costos administrativos, y una mayor burocratización y complejidad de las relaciones de mercado. También contribuyeron a una reducción en la oferta de servicios y posibilitaron el aumento en la rentabilidad de terceros pagadores.

Por lo tanto, a pesar de todos los esfuerzos y los mecanismos ingeniosos e innovadores, la reforma de los años '90 no alcanzó sus principales objetivos: el control de gastos y de costos en salud, y el aumento de cobertura. Estos problemas típicos de gestión de sistema no lograron ser superados por medio de los instrumentos de mercado adoptados.

Por ende, observamos que el sistema de salud de EE.UU. sigue basado en los valores de individualismo y de competencia, compatibilizando medidas de protección pública a grupos sociales específicos con la producción de servicios por el mercado.

El predominio de la lógica de mercado no ha impedido la creciente intervención del Estado en la búsqueda de su regulación. Puede constatarse que la competencia ha permitido el desarrollo de innumerables innovaciones en la gestión financiera, permitiendo el avance de la eficiencia en el nivel micro de la gestión. Sin embargo, el creciente aumento del gasto total en salud como porcentaje del PBI y la persistencia de una parte significativa de la población sin cobertura, nos lleva a la conclusión de la ineficiencia del sistema en el nivel macro.

Es una paradoja que la opción por la eficiencia en detrimento de la equidad haya terminado por generar inequidad con ineficiencia.

b. Coparticipaciones: consiste en participar financieramente del costo de una parte del servicio de salud que es utilizado por el asegurado. Es diferente del pago de la prima del seguro de salud, contribución o tasa, pagados independientemente del cuidado médico recibido. Las formas de cost-sharing son: co-pago (copayment), participación con un valor fijo por cada servicio; co-seguro, porcentajes de los valores de los servicios; y 
las deducciones, que corresponden al monto que el paciente gasta para el cuidado en salud en un determinado período antes de ser efectuados los pagos del seguro.

c. Medicaid presta asistencia a las familias consideradas de renta baja (pobres) y a ancianos indigentes. Regidos por ley federal, los programas estatales Medicaid deben cubrir algunos grupos, como jóvenes hasta 18 años pertenecientes a familias con una renta total por debajo del nivel federal de pobreza. Está permitida la cobertura de mujeres embarazadas y niños menores de un año de vida cuya renta familiar esté entre 133\% a $185 \%$ del nivel de pobreza establecido (7).

d. Managed care, "atención gerenciada", es un término genérico referido a los planes de salud que realizan acciones activas que afectan el tipo y la cantidad de cuidado que reciben sus asociados, con la mejor relación costo-efectividad. Difieren de los planes tradicionales básicamente porque poseen contratos detallados y relaciones laborales con los proveedores de cuidados de salud. Los planes managed care utilizan el requerimiento de autorización previa de servicios, visitas a ciertos especialistas, y hospitalizaciones y contratos selectivos con proveedores como mecanismos de contención de costos (7). En la mayoría de los planes, el usuario solamente tiene acceso a profesionales o servicios que constan en la lista provista por el mismo plan.

e. Guild Model es un sistema con libre elección del médico por parte del paciente, libre prescripción para el médico, entendimiento y negociación directa entre médicos y pacientes con relación a los procedimientos, sin interferencia de terceros y finalmente, pago por servicio (31).

f. Managed competition: la defensa de la mera privatización fue progresivamente sustituida por la noción de "competencia gerenciada", expresión usada por Enthoven para identificar los cambios en las relaciones entre usuarios, financiadores, compradores y prestadores de servicios. En el modelo de competencia gerenciada se asume la imperfección del mercado de servicios sociales, resultante de la asimetría de informaciones y de la incapacidad de hacer factible la compra de servicios sólo con el financiamiento privado, como contingencia que requiere un acuerdo distinto. Por consiguiente, se atribuye al Estado la creación de mecanismos compulsorios de financiamiento y las funciones de normalización y regulación, de forma que garantice que los mercados de seguros y los prestadores de servicios funcionen dentro de las reglas públicas.

g. Las HMOs presentan las siguientes características: operan en base a la competencia; por lo general seleccionan a su clientela; poseen un plantel fijo de profesionales; habitualmente no pagan por prestación, sino por volumen de atención; actúan con referencias, es decir, la atención especializada y las internaciones son abonadas después de autorizadas por los profesionales del cuadro médico; $y$, aunque en términos retóricos, enfatizan la prevención, priorizando la atención ambulatoria (5).

h. Los GRD fueron introducidos en el programa Medicare en 1983: consiste en un sistema prospectivo de pagos a hospitales según grupos de diagnóstico de enfermedades (cerca de 470). De acuerdo a este paquete los hospitales pueden retener las diferencias entre sus gastos efectivos y el pago, o bien asumir el perjuicio.

i. Londoño y Frenk (2) proponen un enfoque de análisis de los sistemas de salud, enfatizando las relaciones entre sus componentes y analizándolo en su conjunto. Los grupos poblacionales tienen necesidades que requieren una respuesta social organizada, estructurada por ciertas funciones básicas. Distingue los servicios de salud personal de los de salud pública y concentra su análisis en los primeros. La configuración de las cuatro funciones más importantes del sistema de salud -modulación, financiamiento, articulación y prestación- permite identificar los principales modelos institucionales. Se define la modulación como la responsabilidad pública medular, centrada en el desarrollo de reglas justas de juego. La articulación se encuentra entre el financiamiento y la provisión, significa organizar y administrar el consumo de la atención. En algunos modelos, ciertas funciones pueden no estar claramente presentadas, o incluso 
ausentes. Esas omisiones son comunes en el caso de la modulación y articulación. Ningún país se constituye en una expresión pura de cualquier modelo. Basado en la concepción de que los sistemas se constituyen de la intersección entre poblaciones e instituciones, identifica los cuatro principales modelos de salud en América Latina: Modelo Público Unificado (Cuba, Costa Rica), Modelo de Contrato Público (Brasil), Modelo Segmentado (la mayoría de países latinoamericanos) y Modelo Privado Atomizado (Argentina, Paraguay). Los Modelos de Salud convergieron hacia una quinta forma, el Pluralismo Estructurado.

j. Las aseguradoras están autorizadas solamente a ofrecer diez planes estandarizados. Además, se solicita a las aseguradoras que ofrezcan sus planes sin verificación médica previa hasta que los beneficiarios completen las condiciones para el Medicare, sea por edad o por otras condiciones previstas por ley (7).

k. El aumento de la coparticipación en los cuidados médicos fue común a partir de los años ' 80 y especialmente en los '90. Fue un fenómeno mundial cuya mayor intensidad se dio en Austria (1988, 1996, 1997), Bélgica (1992-1995), Finlandia (1990-95, 2002), Francia (décadas del '70 y '80), Alemania (década del '90) e Italia (1995). Este incremento afectó principalmente a los fármacos, las internaciones y las visitas médicas tuvieron un crecimiento menor. Los resultados no fueron beneficiosos: las medidas redujeron los gastos públicos pero no el gasto total en salud. En los sistemas sanitarios como el de EE.UU., aumentaron los gastos por desembolso directo y por seguros complementarios. Como la elasticidad entre el precio y la demanda de cuidados de salud es en general baja -entre -0,2 y -0,3- los resultados al nivel de cuidados hospitalarios son bajos. Algunas reducciones en el consumo de servicios, como las consultas con médicos generalistas y algunos exámenes, son incluso indeseadas, porque contribuyen a originar problemas más serios y costosos en el futuro. Por lo tanto, los incrementos en los co-pagos, suficientes para tener efectos significativos en la demanda, presentaron efectos indeseables en el acceso y adicionaron costos sociales. A causa de esto, muchos países han atenuado esos efectos eximiendo a grupos vulnerables, estableciendo topes máximos en los gastos en salud y permitiendo seguros complementarios para cubrir los co-pagos (9).

I. Estas eran organizaciones complejas, con carácter mandatario, a las alianzas regionales de salud. Sin fines de lucro, independientes de las agencias estatales o de filiales ejecutivas de esas agencias y con un conjunto de poderes extraordinarios. Las Alianzas debían inscribir a todas las personas elegibles en su área de actuación, actuar como compradoras de servicios de salud para todos los empleadores con menos de 5.000 funcionarios, controlar el acceso a todos los planes de salud, mantenerse al tanto de nuevas versiones de planes, monitorear las prácticas de marketing de los planes, controlar y definir los términos de relación con todos los planes de salud calificados, definir niveles de primas, recolectar y desembolsar subsidios federales y usar mecanismos de ajuste de riesgo para equilibrar las variaciones de estado de salud en los beneficiarios entre los diferentes planes de salud. Las compañías con más de 5.000 empleados podrían formar sus propias alianzas corporativas pero tendrían que proveer los mismos paquetes de beneficios garantizados federalmente $y$ seguir todas las directrices gubernamentales. Las Alianzas recibirían 2,5\% del valor de las primas para costear sus gastos administrativos.

$\mathrm{m}$. Este principio produjo gran polémica en los EE.UU. Entre las ventajas, aumentaría el compromiso con la cobertura universal, mantendría la tradición americana del sistema de seguros basado en el empleo y reduciría los costos de la planilla de pagos de las empresas que asegurasen a sus funcionarios. Como desventajas, perpetuaría el mito de que la compañía paga por el cuidado de salud, tendería a ser regresivo en la incidencia de los costos asociados, el costo de los beneficios tendería a retornar a los emplea- 
dos en forma de menores salarios y tendría un efecto negativo sobre el empleo para las empresas menores que no ofrecieran tal beneficio a empleados con bajos salarios (32).

n. Según recientes estimaciones, los fraudes y sobrepagos en el sistema Medicare alcanzaban al $14 \%$ de los pagos federales, lo que equivalía a US\$23 mil millones por año (20).

o. Fee for service es una modalidad de pagos en la cual el prestador de servicio es remunerado de acuerdo con cada acto o servicio prestado (33).

p. En 1998 fue introducido el PPS para servicios especializados de enfermería -Resource Utilization Groups (RUG)-, basado en un sistema con 44 grupos de cuidados residenciales de enfermería. Posteriormente, fue implantado el PPS para la atención ambulatoria, el Ambulatory Payment Classifications (APCs), que clasifica procedimientos, servicios de evaluación, drogas y equipos en ambulatorios en 750 tipos, clínicamente similares y con recursos comparables. En el 2000, el PPS fue introducido para servicios domiciliares de salud, el Home Health Resource Groups (HHRGs), con 80 grupos, basados en diagnóstico, capacidad funcional y servicios.

q. Resource Utilization Groups (RUG): sistema para el agrupamiento de cuidados residenciales de enfermería de acuerdo con su status clínico y funcional, identificado por la información de cuidados mínimos.

\section{REFERENCIAS BIBLIOGRÁFICAS}

1. Evans R. Incomplete vertical integration: the distinctive structure of the Health-care. En: Van der Gaag J, Perlman M, editores. Health, Economics and Health Economics. Amsterdam: North Holland Publishing; 1981.

2. Londoño JL, Frenk J. Pluralismo estructurado: hacia un modelo innovador para la reforma de los sistemas de salud en América Latina. México: Fundación Mexicana de la Salud; 1997.

3. Fleury S. Estado sem cidadãos. Río de Janeiro: Ed. Fiocruz; 1994.

4. Lobato LV. Reforma do Estado no setor de salud no Reino Unido e nos Estados Unidos. En: Reforma do Estado no setor de saúde: os casos da Catalunha, Canadá, Reino Unido e Estados Unidos. Cadernos ENAP. 1997;13:79-113.

5. Almeida CM. As reformas sanitárias dos anos 1980. Crise ou Transição?. [Tesis de doctorado]. Rio de Janeiro: ENSP/FIOCRUZ; 1995.

6. Davis K. Time for change: the hidden cost of a fragmented health insurance system. Senate special Committee on aging. New York: The Commonwealth Fund; 2003.

7. Organization for Economic Cooperation and Development. The US Health System: a assessment and prospective directions for reform. Economics Department Working Papers 350. Paris: OECD; 28 de febrero de 2003.
8. Organization for Economic Cooperation and Development. Stroke Care in OECD Countries: A Comparison of Treatment, Costs and Outcomes of 17 Countries. OECD Health Working Papers 5. Paris: OECD; 6 de junio de 2003.

9. Organization for Economic Cooperation and Development. Health-care Systems: Lessons from the Reform Experience. OECD Health Working Papers 9. Paris: OECD; 5 de diciembre de 2003.

10. Goldsmith J. The Failed Clinton Health Reforms: Is Manages Competition A Viable Policy Paradigm? [en línea]. Unpublished paper 1995 [fecha de acceso 8 de enero de 2004]. URL disponible en: http://www.healthfutures.net/pdf/w-clnt.pdf

11. Media Monitor. Diagnosing Health care Reform. Media Monitor [en línea]. Mayo-Junio 1994 [fecha de acceso 8 de enero de 2004]; VIII (3). URL disponible en: http://www.cmpa.com/ mediaMonitor/MediaMonitorArchive.htm

12. Cuneo G. What the Clinton Health Reform Plan Means to You [en línea]. 1993 [fecha de acceso 8 de enero de 2004]. Dynamic Chiropractic; 11 (22). URL disponible en: www.chiroweb.com/ archives/11/22/16.html

13. Cohodes DR. Pragmatism And Health Care Reform. Health Affairs 1994; 13 (1): 264-273.

14. Rotschild M. Why Health Care Reform Died. The Wall Street Journal. 22 de setiembre de 1994. 
15. Robbins A, Robbins G. Forecasting the Effects of the Clinton Health Plan. National Center for Policy Analysis, NCPA. Texas Policy Report 185 mayo de 1994.

16. Lane JA. A Workable Framework For Health Reform. Health Affairs 1994; 13 (1): 248-250.

17. Landau M. Health Care Reform: autopsy of a proposal [en línea]. 1994 [fecha de acceso 8 de enero de 2004]. URL disponible en: http://focus.hms.harvard.edu/1994/Nov4_1994/ Health_Care.html

18. Gabel J, Derek L, Jensen G, Marsteller J. The health insurance picture in 1993: Some rare good news. Health Affairs. 1994;13(1):327-336.

19. Hodge SA, Freeman G. The Federal Budget: How to Get Spending Under Control. Washington (DC): The Heritage Foundation's Policy Papers; 1998.

20. Craig LE. Look at the impact of BBA'1997 on Medicare payments: Clinton administration culpable on Medicare [en línea]. 1 de octubre de 1999 [fecha de acceso 1 de marzo de 2004]. URL disponible en: http://rpc.senate.gov/ files/100199BBA97 Medicare.pdf

21. Health Care Financing Administration. Ways and means Comittee WMCP. Office of the Actuary, HCFA. Green Book; 2000.

22. Michigan Health \& Hospital Association, MHA. No margin, no mission: The financial realities of Michigan's nonprofit hospitals [en línea]. [Fecha de acceso 1 de marzo de 2004]. URL disponible en: www.mha.org/margin/.

23. Association of Hospitals and Health Systems. BBA \& BBRA Impact on Georgia Hospitals 19982004. Georgia: GHA; 1998.

24. National Association for Home Care: News Release. Medicare reform legislation bill eliminates a scheduled $15 \%$ cut for home health without imposing injurious home health copays. [En línea] $28 \mathrm{de}$ junio de 2002 [fecha de acceso 1 de marzo de 2004]. URL disponible en: http://www.nahc.org/ NAHC/NewsInfo/02nr/MedReformLeg.html
25. Altman SH. Health Care review. New York: Deloitte \& Touche; 2003.

26. Center for Medicare \& Medicaid Services. Health Care Industry Market Update, Nursing Facilities. CMS 6 de febrero de 2002.

27. Empire Medicare Sevices. Important Medicare Part A News. Empire Medicare Services, a CMS Contracted Agent [en línea]. 7 de octubre de 2001 [fecha de acceso 8 de marzo de 2004]. URL disponible en: http://www.empiremedicare.com/PDF/MNU/mnu2001-10.pdf

28. Stark P. More Medicare HMO cutbacks coming: some thoughts to take into consideration. Congressman Pete Stark's Press Release [en línea]. 11 de mayo de 2000 [fecha de acceso 4 de marzo de 2004]. URL disponible en: http:// www.house.gov/stark/webarchives/Stark \%20We b\%20Page/documents/106th/hmocuts.html\#Anc hor-35882

29. Altman $\mathrm{SH}$, Tompkins ChP, Eilat E, Glavin MPV. Escalating Health Care Spending: Is It Desirable Or Inevitable [en línea]. Health Affairs - Web Exclusive 8 de enero de 2003 [fecha de acceso 4 de marzo de 2004]. URL disponible en: http://content.healthaffairs.org/cgi/content/full/hlt haff.w3.1v1/DC1

30. Pauly MV. Should be worried about high real medical spending growth in the United States? [en línea]. Health Affairs - Web Exclusive 8 de enero de 2003 [fecha de acceso 4 de marzo de 2004]. URL disponible en: http://content.healthaffairs.org/cgi/content/full/hlthaff.w3.15v1/DC1

31. Enthoven A. Theory and practice of managed competition in health care finance. Amsterdam: Elsevier Science Publishers; 1988.

32. Reinhadt UE. The Clinton Plan: A Salute to American Pluralism. Health Affairs. 1994;13(1): 161-178.

33. Organization for Economic Cooperation and Development. The Reform of Health Care - A Comparative Analysis of Seven OECD Countries. Paris: OECD; 1992. 


\section{BIBLIOGRAFÍA DE CONSULTA}

Boccuti C, Moon M. Comparing Medicare And Private Insurers: Growth Rates In Spending Over Three Decades. Health Affairs. Marzo-Abril 2003; $22(2): 230-237$.

Fleury S, Belmartino S, Baris E. Reshaping Health Care in Latin America - A comparative Analysis of Health Care Reform in Argentina, Brazil, and Mexico. Ottawa: IDRC; 2000. p. 3-24.

Health Insurance Portability and Accountability Act of 1996. Summary of administrative Simplification Provisions [en línea]. 1996 [fecha de acceso 1 de marzo de 2004]. URL disponible en: http://www.cms.hhs.gov/hipaa/hipaa2/general/ background/h3103sum.asp

Heffler S, Smith S, Keehan S, Clemens MK, Won G, Zezza M. Health Spending Projections for 2002-2012 [en línea] Health Affairs - Web Exclusive febrero de 2003 [fecha de acceso 8 de marzo de 2004]. URL disponible en: http://content. healthaffairs.org/cgi/reprint/hlthaff.w3.54v1

Oberlander JB. True reform to secure Medicare's financial future should include change in the payroll tax [en línea]. 24 de Julio de 1999 [fecha de acceso 8 de enero de 2004]. URL disponible en: http://www.unc.edu/news/archives/jul99/ oberlander072999.htm

President's Advisory Commission on Consumer Protection and Quality in the Health Care Industry: Consumer Bill of Rights and Responsabilities. Executive Summary [en línea]. 1997 [fecha de acceso 21 de enero de 2004]. URL disponible en: http://www.hcqualitycommission.gov/press/cbor.html
Robbins A, Robbins G. Forecasting the Effects of the Mitchell Health Bill. National Center for Policy Analysis - NCPA. Texas Policy Report 186 setiembre de 1994.

The Commonwealth Fund. Time for change: the hidden cost of a fragmented health insurance system. Invited Testimony In Critical Condition: America's Ailing Health Care System. Senate Special Committee on Anging. 10 de marzo de 2003.

The New York Times. Americanos poderão pagar taxa extra por serviço de salud. The New York Times [en línea]. 14 de octubre de 2003 [fecha de acceso 14 de octubre de 2003]. URL disponible en: http://noticias.uol.com.br/midiaglobal/nytimes/ ult574u3365.jhtm.

The World factbook. Central Intelligence Agency [en línea]. 2003 [fecha de acceso 12 de octubre de 2003]. URL disponible en: http://www.odci.gov/ cia/publications/factbook/geos/us.html

A Detailed Timeline of the Healthcare Debate portrayed in The System [en línea]. 1996 [fecha de acceso 8 de marzo de 2004]. URL disponible en:http://www.pbs.org/newshour/forum/may96/ background/health_debate_page $2 . \mathrm{html}$ 